\title{
Sistem Pengaturan Suhu Boiler pada Sterilisasi Baglog dengan Kontrol PI
}

\author{
Supriatna Adhisuwignjo ${ }^{1}$, Mila Fauziyah ${ }^{2}$, Denda Dewatama ${ }^{3}$, Kris Witono ${ }^{4}$, Achmad Wildan Maulana ${ }^{5 *}$ \\ 1,2,3,5 Teknik Elektronika, Politeknik Negeri Malang, Malang, Indonesia \\ ${ }^{4}$ Teknik Mesin, Politeknik Negeri Malang, Malang, Indonesia \\ ( ${ }^{*}$ wildanbareng05@gmail.com)
}

\begin{abstract}
Abstrak - Jamur tiram (Pleurotus ostreatus) merupakan jamur kayu yang tumbuh berderet menyamping pada batang kayu lapuk. Sterilisasi merupakan proses budidaya jamur tiram. Sterilisasi digunakan untuk membunuh mikrooganisme pengganggu yang dapat menghambat pertumbuhan jamur. Boiler adalah salah satu mesin yang memanfaatkan uap air panas untuk proses sterilisasi baglog. Boiler diisi air lalu dipanaskan agar hingga mencapai suhu $80^{\circ} \mathrm{C}-110^{\circ} \mathrm{C}$, lalu uap air akan disuplai ke steamer untuk proses sterilisasi. Sistem pengaturan suhu boiler pada sterilisasi baglog dengan metode kontrol PI ini bertujuan untuk menjaga suhu agar tetap pada set point. Alat ini memudahkan seseorang untuk memonitoring suhu dalam boiler tanpa harus khawatir jika ada kesibukan yang lainnya. Alat ini dilengkapi dengan sensor suhu thermocouple $\mathrm{K}$ untuk membaca suhu pada boiler, dan motor DC digunakan untuk mengontrol putaran pada katup kompor yang mengatur besar kecilnya api pemanas, lalu LCD 16 X2 untuk menampilkan suhu terbaca pada boiler yang dihubungkan ke Arduino UNO R3 sebagai mikrokontroler.
\end{abstract}

Kata kunci: Arduino UNO R3; boiler; motor DC; sterilisasi baglog; thermocouple K

\section{PENDAHULUAN}

Jamur tiram adalah jenis jamur yang cukup populer sebagian besar masyarakat Indonesia (Pranada $\mathrm{H}$, 2012). Jamur banyak digemari karena rasanya yang enak serta mempunyai banyak sekali manfaat untuk Kesehatan (LD Putri, 2020). Terdapat protein dan karbohidrat yang tinggi serta kalori yang rendah. Jamur tiram putih mengandung protein, lemak, fosfor, besi, thiamin dan riboflavin lebih tinggi dibandingkan jenis jamur lain. Mikroelemen yang bersifat logam sangat rendah sehingga aman dikonsumsi setiap hari. Maka untuk dapat menghasilkan jamur tiram yang memiliiki kualitas gizi bagus dan baik diperlukan media tanam yang mendukung pertumbuhannya. Media tanam harus memiliki proses sterilisasi jamur yang baik dan benar untuk mencukupi nilai gizinya (Nurjanah S, 2015).

Perkembangan teknologi di zaman ini dapat menjadi pendukung untuk mengembangkan alat sterilisasi baglog. Boiler adalah alat yang mampu merubah air menjadi uap air yang dapat dimanfaatkan tekanan maupun panas dari uap air tersebut. Alat ini memanfaatkan boiler untuk proses pengolahan dan pemanasan dengan memanfaatkan panas dari uap air yang dihasilkan. Dimana boiler ini berisi air, air di dalam boiler dipanaskan sehingga mendidih sampai menghasilkan uap, lalu uap yang dihasilkan akan mengalir ke streamer untuk proses sterilisasi baglog. Boiler dan steamer menjadi satu kesatuan alat yang digunakan sebagai sterilisasi baglog jamur tiram. Adanya boiler akan mempercepat proses penguapan yang nantinya akan disuplai ke steamer.

Proses budidaya jamur saat ini masih mengandalkan sistem yang konvensional yaitu proses menggunakan kayu bakar untuk merebus air dan agar proses pelapukan terjadi secara merata baglog harus dibolak-balikkan secara manual, maka dari itu diperlukan sistem yang dapat menghemat biaya, waktu dan tenaga (Riwandi, R., Merakati, H., \& Hasanudin, H, 2014). Sistem kontrol modern untuk sterilisasi baglog jamur saat ini memerlukan metode kontrol suhu yang tepat untuk mengontrol suhu pada boiler. Penelitian ini diambil berdasarkan riset pada mitra, karena di daerah sekitar ingin meningkatkan alat sterilisasi baglog yang semula manual menjadi otomatis dan memperbanyak kapasitas baglog yang akan disterilisasi. Sehingga masyarakat lebih mudah untuk melakukan sterilisasi. Lalu dengan sekali proses sterilisasi mendapat hasil baglog yang lebih banyak dan optimal dari sterilisasi manual. Metode PI bisa menjadi alternatif untuk pengontrolan suhu pada boiler karena dapat mengatur putaran motor pada kompor secara otomatis. 


\section{STUDI LITERATUR}

\section{A. Sterilisasi Baglog}

Jamur tiram (Pleurotus ostreatus) merupakan jamur kayu yang tumbuh berderet menyamping pada batang kayu lapuk (Wiranto B, 2013). Media tanam jamur tiram atau yang biasa disebut baglog sesudah terpacking harus di sterilisasi agar media benar-benar dapat mencukupi kebutuhan nutrisi jamur, karena nantinya nutrisi dari baglog yang akan mempengaruhi pertumbuhan jamur tiram. Sterilisasi media tanam baglog merupakan salah satu proses penting untuk membunuh mikrooganisme pengganggu yang dapat menghambat pertumbuhan jamur (Ramdhani, A. H., Soelistyono, R, 2020). Sterilisasi umumnya dilakukan dengan merebus air di dalam boiler hingga mencapai suhu setpoint agar dapat menghasilkan uap. Lalu uap akan didistribusikan ke dalam steamer lewat pipa.

\section{B. Boiler}

Boiler atau ketel uap adalah mesin kalor yang berfungsi merubah mengirim energi kimia menjadi energi mekanik. Bentuk boiler adalah seperti bejana tertutup yang bertujuan untuk menghasilkan steam atau uap. Boiler pada dasarnya terdiri dari drum yang tertutup pada ujung atas dan biasanya dilengkapi oleh pipa api atau pipa air (Purba J, 2016).

\section{Sistem Kendali PI}

Kontrol PI merupakan sistem kontrol yang berasal dari gabungan sistem kontrol proposional dan sistem kontrol Integral, dimana kedua sistem kontrol tersebut disatukan untuk mengontrol sebuah plant (Rudiyanto, B., Susanto, A., \& Susmiati, Y, 2016). Nilai konstanta tersebut pada sistem PI perlu diatur, karena dengan mengatur nilai konstanta pada masing-masing sistem kontrol yaitu sistem kontrol proporsional dan sistem kontrol integral akan didapatkan hasil pengontrolan yang baik, yaitu response time semakin cepat, temperatur lebih stabil, dan proses penentuan nilai konstanta pada sistem kontrol PI. Pada penelitian ini diperoleh berdasarkan proses perhitungan dengan menggunakan metode ke-1 Ziegler-Nichols. Metode Ziegler Metode ke-1 didasarkan pada respon plant terhadap masukan tangga dalam kalang terbuka. Plant yang tidak mempunyai integrator, menghasilkan kurva tanggapan terhadap masukan tangga seperti kurva huruf S pada Gambar 1. Kurva tanggapan plant digunakan untuk mencari waktu tunda L dan konstanta waktu.

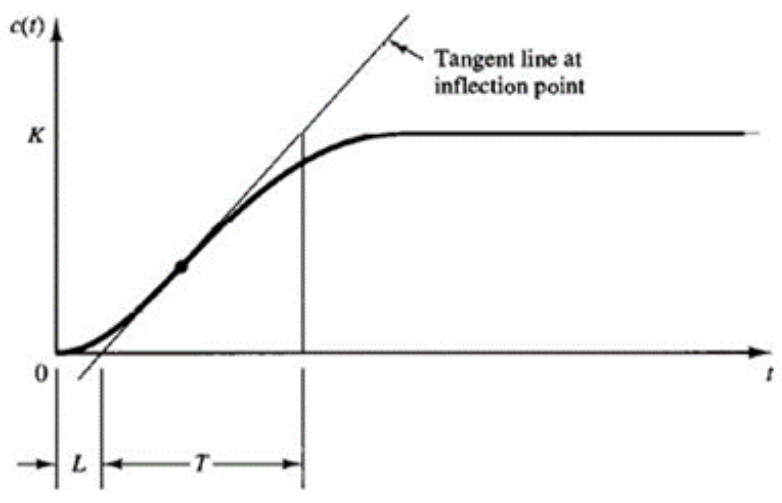

Gambar 1. Kurva Tanggapan

\section{Motor DC}

Motor DC merupakan perangkat yang mengubah tenaga listrik menjadi tenaga kinetik. Motor DC ini dapat disebut juga Motor Arus Searah. Seperti namanya, DC Motor memiliki dua terminal serta membutuhkan tegangan arus DC atau arus searah untuk dapat menggerakkan motor tersebut (Putra M.S, 2019). Motor DC ini menghasilkan putaran per menit atau biasa disebut dengan RPM (Revolutions per minute) dan dapat diatur arah berputarnya, berputar searah jarum jam atau berlawanan hanya dengan mengganti polaritas listrik yang diberikan pada Motor DC. Sebagian besar Motor DC dapat memberikan kecepatan rotasi kurang lebih 3000 
rpm hingga $8000 \mathrm{rpm}$ dengan tegangan dari 1,5V hingga 24V (Naim M, 2021). Jika tegangan yang diberikan ke Motor DC lebih kecil dari tegangan operasionalnya maka rotasi Motor DC akan menjadi lambat begitupun sebaliknya, jika tegangan yang diberikan lebih tinggi dari tegangan operasional maka rotasi motor DC akan menjadi cepat.

Motor DC tipe 37GB31ZY, dengan spesifikasi sebagai berikut.

1) Shaft diameter 6mm D-shaped shaft

2) Perbandingan Gear: 1:56

3) Speed: 110RPM

4) Power Consumption Standard: $<=1 \mathrm{~A}$

5) Torque: $11.2 \mathrm{kgcm}$

Motor DC pada alat ini akan digunakan untuk mengontrol putaran kompor sesuai dengan setpoint suhu yang sudah ditentukan.

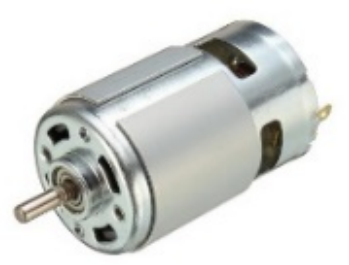

Gambar 2. Motor DC

\section{METODOLOGI}

\section{A. Diagram Blok Sistem}

Dalam blok diagram ini terdapat blok input, proses, output. Dalam blok input terdapat sensor suhu Thermocouple K dan driver MAX6675 untuk mengkonversi keluaran thermocouple menjadi tegangan agar dapat di proses oleh Arduino Uno. Dan di blok output terdapat driver IBT 2 untuk memproses putaran kanan dan kiri pada motor DC, karena jika motor DC tidak menggunakan driver maka motor DC tidak bisa berputar ke kanan dan ke kiri. LCD untuk display tampilan suhu yang terbaca pada boiler dan setpoint suhu.

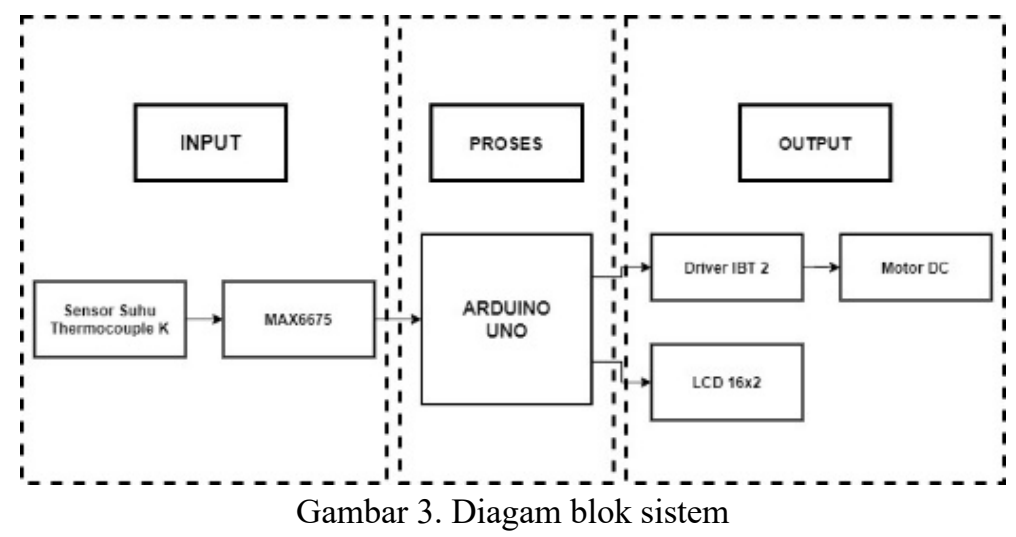

\section{B. Perancangan Mekanik Boiler}

Boiler dibuat dari besi untuk bisa bertahan dengan suhu dan tekanan air yang tinggi. Boiler ini dilengkapi dengan sight glass water level untuk mengetahui level air pada boiler, lalu pressure gauge untuk mengetahui tekanan di dalam boiler, serta safety valve untuk membuang tekanan berlebih pada boiler. 


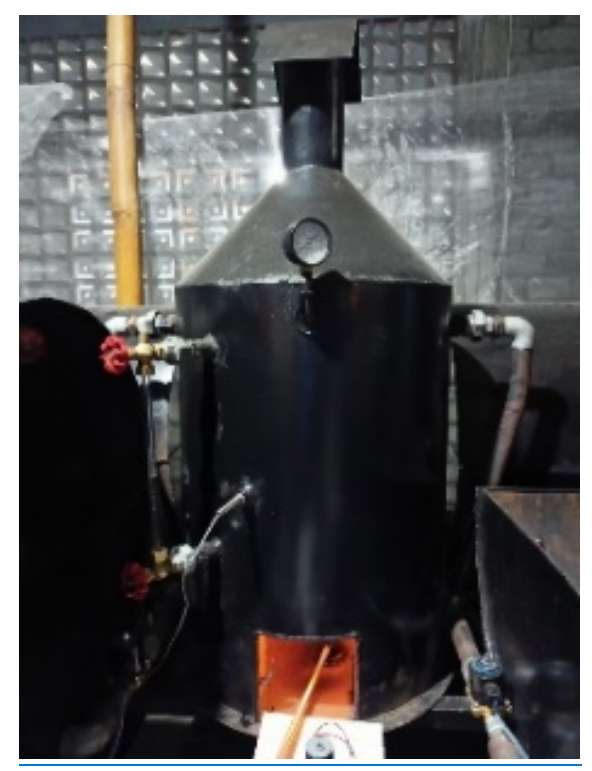

Gambar 4. Mekanik boiler

Sebelum boiler mensuplai uap, air dipanaskan terlebih dahulu sampai suhu setpoint atau $80^{\circ} \mathrm{C}-110^{\circ} \mathrm{C}$. Lalu setelah suhu mencapai setpoint uap air akan disuplai ke steamer. Jika steamer belum membutuhkan suplai air dari boiler, maka uap akan dikeluarkan terlebih dahulu melalui safety valve agar tidak terjadi tekanan yang berlebih.

\section{Perancangan Software}

Sebelum membuat software atau coding di dalam Arduino, langkah awal yang dilakukan adalah merancang flowchart seperti pada Gambar 5.

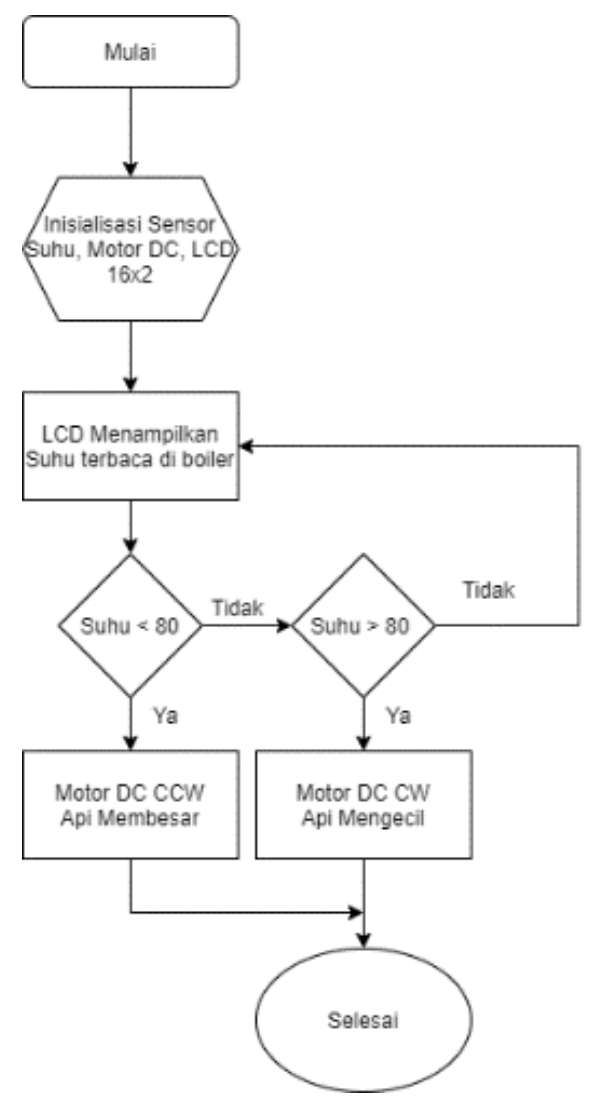

Gambar 5. Flowchart 
Pada flowchart ini menjelaskan kinerja boiler. Ketika alat dinyalakan, lcd akan menampilkan suhu yang terbaca pada boiler dan setpoint suhu yang sudah ditentukan. Apabila suhu terbaca kurang dari suhu setpoint maka motor dc akan berputar CCW dan api akan membesar. Lalu ketika suhu terbaca lebih dari setpoint maka motor dc akan berputar CW dan api akan mengecil.

\section{Perancangan Elektronik}

1) Perancangan Sensor Suhu Thermocouple $K$

Termokopel tipe K adalah jenis termokopel yang paling umum. Sensor suhu ini mempunyai rentang suhu yang luas antara -200 - $900 \mathrm{C}$. Thermocouple K disambukan ke pin + dan - pada MAX6675, lalu pin pada MAX6675 disambungkan pada Arduino dengan pin sebagai berikut, (-) Pin VCC ke 5V Arduino, (-) Pin GND ke GND Arduino, (-) Pin SO ke pin 4 Arduino, (-) Pin CS ke pin 5 Arduino, (-) Pin SCK ke pin 6 Arduino.

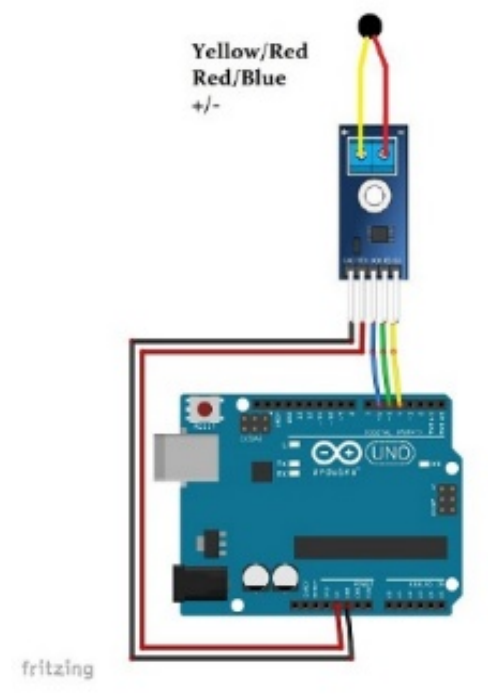

Gambar 6. Rancangan Thermocouple K

2) Perancangan Kontrol PI

Kontroler PI memiliki 2 parameter yang berpengaruh pada kinerja kontroler ini yaitu konstanta proposional (Kp), konstanta integral (Ki). Pada perancangan kontroler menggunakan tuning parameter Ziegler-Nichols metode pertama. Langkah pertama yang dilakukan adalah mengambil respon dari plan dapat diperoleh secara eksperimental dengan masukan unit step, untuk mendapatkan nilai Tu dan Ta. Hasil Simulasi didapatkan model sistem yang telah didesain maka dapat ditentukan $\mathrm{L}$ dan $\mathrm{T}$ dari kurva respon. Setelah didapatkan fungsi alih dari unit step Langkah selanjutnya adalah menghitung nilai $\mathrm{Kp}$, Ti, dan Td sesuai dengan aturan ZieglerNichols.

$\mathrm{Kp}=1,2 \mathrm{~T} / \mathrm{L}$

$\mathbf{T i}=\mathbf{2 L}$

Nilai Ki didapatkan menggunakan perhitungan $\mathrm{Ki}=\mathrm{Kp} / \mathrm{Ti}$

Tabel 1

Parameter Pi dengan metode kurva Ziegler-Nichols

\begin{tabular}{cll}
\hline $\begin{array}{c}\text { Tipe } \\
\text { Kontroler }\end{array}$ & \multicolumn{1}{c}{$\mathrm{Kp}$} & \multicolumn{1}{c}{$\mathrm{Ki}$} \\
\hline $\mathrm{P}$ & $\mathrm{T} / \mathrm{L}$ & $\sim$ \\
$\mathrm{PI}$ & $0,9 \mathrm{~T} / \mathrm{L}$ & $\mathrm{L} / 0,3$ \\
\hline
\end{tabular}

Untuk pengambilan kurva respon plant dengan memberi masukan setpoint (unit step). nilai setpoint yang akan dipakai harus ditentukan terlebih dahulu sebelum mencari grafik respon. Dalam perancangan sistem kontrol PI menggunakan setpoint. Hasil pengujian respon suhu terhadap waktu dapat dilihat pada gambar di bawah ini. 


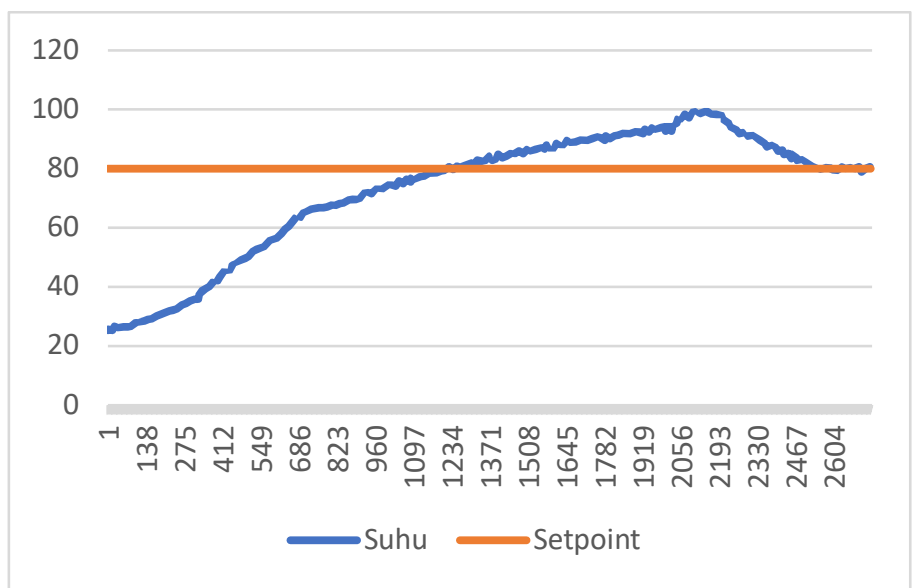

Gambar 7. Kurva respon

Menurut respon grafik perubahan suhu terhadap waktu diperoleh data:

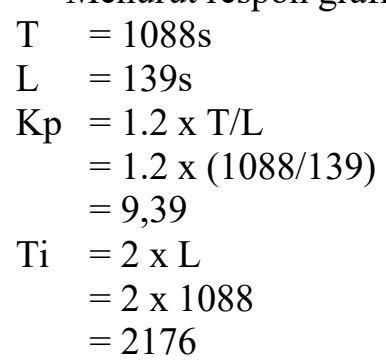

Parameter kontrol PI plant sebagai berikut:

$$
\begin{aligned}
\mathrm{Kp} & =9,39 \\
\mathrm{Ki} & =\mathrm{Kp} / \mathrm{Ti} \\
& =9,39 / 2176 \\
& =0,0043
\end{aligned}
$$

Dengan menggunakan metode kurva reaksi Ziegler-Nichols maka didapatkan hasil tunning parameter PI yaitu $\mathrm{Kp}=9,39, \mathrm{Ki}=0,0043$

\section{3) Perancangan Rangkaian Motor DC}

Motor DC disini digunakan untuk memutar regulator gas sesuai dengan suhu yang terbaca. Motor DC menggunakan driver BTS7960 untuk koneksi ke Arduino Uno dengan pin sebagai berikut, (-) + Motor DC ke pin M+ pada driver, (-) - Motor DC ke pin M- pada driver, (-) V+driver ke Power Supply + (-) V-driver ke Power Supply - , (-)Pin VCC driver ke 5V Arduino, (-) Pin GND driver ke GND Arduino, (-) Pin RPWM driver ke pin 9 Arduino, (-) LPWM driver ke pin 10 Arduino, (-) Pin R_EN driver ke pin 11 Arduino, (-) Pin L_EN driver ke pin 12 Arduino.

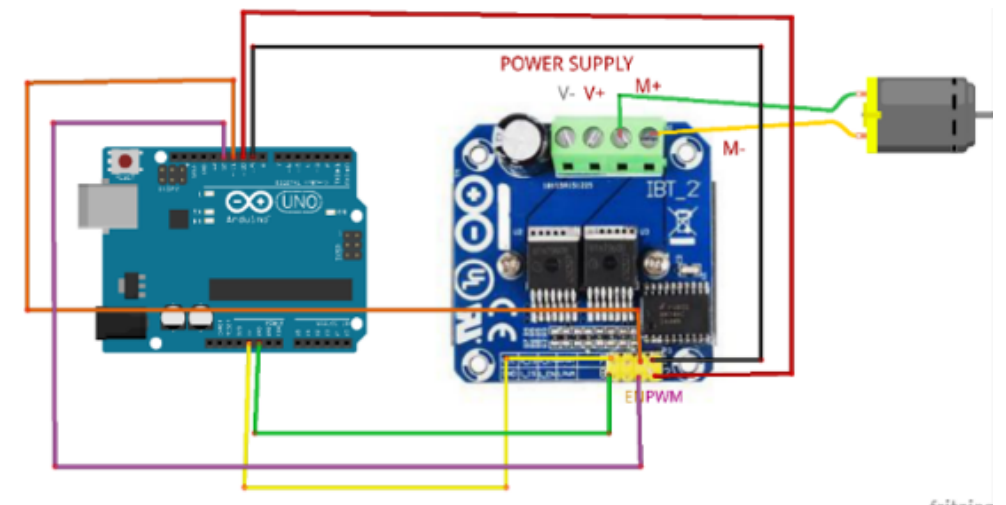

Gambar 8. Rancangan motor DC 


\section{HASIL DAN DISKUSI}

\section{A. Pengujian Sensor Suhu}

Pada pengujian sensor suhu pertama kali sensor dikalibrasi. Suhu terbaca di sensor suhu dibandingkan dengan suhu terbaca di termometer. Data pengujian ini dilakukan dengan mengambil data berdasarkan kenaikan suhu setiap $5^{\circ} \mathrm{C}$.

Tabel 2

Pengujian sensor suhu thermocouple $\mathrm{K}$

\begin{tabular}{cccc}
\hline No & $\begin{array}{c}\text { Thermocouple } \mathrm{K} \\
\left({ }^{\circ} \mathrm{C}\right)\end{array}$ & $\begin{array}{c}\text { Termometer } \\
\left({ }^{\circ} \mathrm{C}\right)\end{array}$ & Error $(\%)$ \\
\hline 1 & 27,5 & 27,1 & 0,3 \\
2 & 32,25 & 32 & 0,25 \\
3 & 37,25 & 36,9 & 0,35 \\
4 & 42,75 & 42,4 & 0,35 \\
5 & 47 & 47 & 0 \\
6 & 52,5 & 52,2 & 0,3 \\
7 & 57,5 & 57,2 & 0,3 \\
8 & 62,25 & 61,9 & 0,35 \\
9 & 67 & 67 & 0 \\
10 & 72,75 & 72,4 & 0,35 \\
\hline \multicolumn{5}{c}{}
\end{tabular}

Hasil pengujian sensor thermocouple $\mathrm{K}$ dibandingkan dengan termometer dan menggunakan program untuk menampilkan suhu terbaca pada LCD menunjukkan bahwa pembacaan sensor thermocouple $\mathrm{K}$ dikatakan baik karena masih memiliki rata-rata error $0,255 \%$.

\section{B. Pengujian Motor DC}

Pengujian driver motor BTS7960 dan motor DC bertujuan untuk memastikan driver ini berjalan dengan baik atau tidak. Untuk pengujian driver motor ini dilakukan dengan memberi PWM pada driver motor, lalu diukur tegangan yang dikeluarkan oleh driver motor yang nantinya akan menggerakkan motor DC sesuai besar tegangan yang dikeluarkan

Tabel 3

Pengujian Motor DC

\begin{tabular}{cccc}
\hline \multirow{2}{*}{ No } & \multirow{2}{*}{ PWM } & \multicolumn{2}{c}{ Kondisi } \\
\cline { 3 - 4 } & & Motor & Tegangan Output \\
\hline 1 & 0 & Mati & $0 \mathrm{~V}$ \\
2 & 50 & Nyala & $2.2 \mathrm{~V}$ \\
3 & 100 & Nyala & $4 \mathrm{~V}$ \\
4 & 150 & Nyala & $6.5 \mathrm{~V}$ \\
5 & 200 & Nyala & $9.2 \mathrm{~V}$ \\
6 & 250 & Nyala & $11.8 \mathrm{~V}$ \\
\hline
\end{tabular}

Pada Tabel 3 dapat dilihat bahwa motor DC bekerja dengan baik karena driver motor mengeluarkan tegangan yang linier dengan pertambahan PWM. Motor DC akan bekerja saat PWM diatur 50 dengan tegangan output 2.2V lalu batas atas motor DC bekerja adalah saat PWM 250 dengan tegangan output 11.8V. Jika motor dc bekerja di tegangan output lebih dari $12 \mathrm{~V}$ maka motor atau driver motor akan mengalami kerusakan.

\section{Pengujian Kontrol PI}

Pengujian kontrol PI dengan menggunakan nilai $\mathrm{Kp}=9,39, \mathrm{Ki}=0,0043$. Hasil dari respon pengujian menggunakan kontroler PI dapat dilihat pada Tabel 4. 
Tabel 4

Pengujian Kontrol PI

\begin{tabular}{cccc}
\hline No & Waktu (Menit) & Suhu $\left({ }^{\circ}\right)$ & Posisi Motor DC \\
\hline 1 & 0 & 26.5 & CCW \\
2 & 5 & 37,5 & CCW \\
3 & 10 & 50,75 & CCW \\
4 & 15 & 71,25 & CCW \\
5 & 20 & 80,25 & CCW \\
6 & 25 & 79,5 & CCW \\
7 & 30 & 80,5 & CCW \\
8 & 35 & 79,25 & CCW \\
9 & 40 & 80,25 & CW \\
10 & 45 & 77 & CCW \\
11 & 50 & 80,25 & CW \\
12 & 55 & 79,75 & CCW \\
13 & 60 & 26.5 & CW \\
14 & 65 & 37,5 & CCW \\
15 & 70 & 50,75 & CW \\
16 & 75 & 71,25 & CCW \\
\hline
\end{tabular}

Hasil respon grafik dapat dilihat pada Gambar 9.

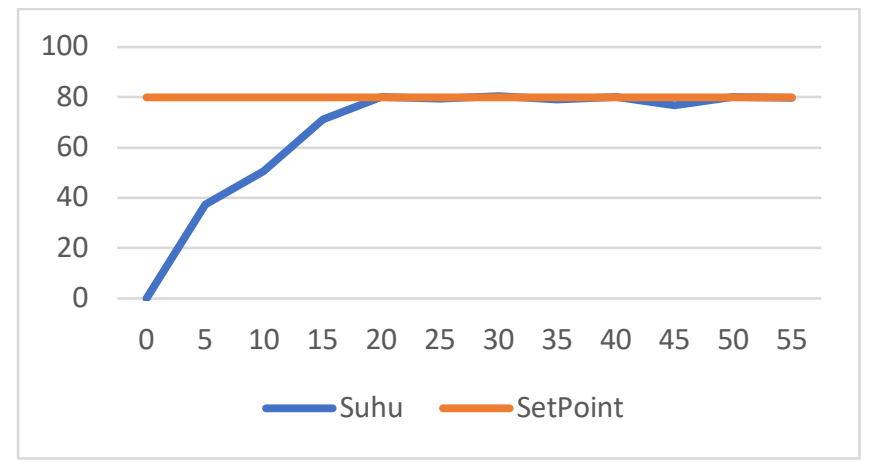

Gambar 9. Grafik respon kontrol PI

Dapat dilihat pada grafik di atas, Pada saat suhu sudah menyentuh $80^{\circ} \mathrm{C}$ maka motor de dengan perlahan berputar untuk mengecilkan api, dan saat suhu lebih dari $80^{\circ} \mathrm{C}$ motor dc akan berputar untuk membesarkan api. Alat bekerja dengan cukup stabil, hanya saja sedikit terjadi penurunan suhu.

\section{KESIMPULAN}

Dari hasil penelitian didapatkan kesimpulan sebagai berikut, Alat sudah berjalan sesuai keinginan, hanya saja ada penurunan yang signifikan $\mathrm{ke} 77^{\circ} \mathrm{C}$ tetapi masih dalam batas wajar, karena setelah suhu turun motor langsung merespon cepat dengan membesarkan api dan kembali lagi ke suhu $80^{\circ} \mathrm{C}$. Berdasarkan data respon sistem yang diperoleh dari pengujian dengan metode Ziegler-nichols, maka parameter kontroler PI dapat ditentukan dengan gain $\mathrm{Kp}=9,39, \mathrm{Ki}=0.0043$. Hasil pengujian ini menunjukkan bahwa pengendalian suhu dengan metode kontrol PI menghasilkan respon sesuai dengan yang diharapkan dan mampu diaplikasikan pada sistem pengendalian suhu karena error yang didapatkan maksimal sebesar $0.255 \%$ dan masih dalam toleransi. Jadi, Motor DC bekerja dengan baik karena driver motor mengeluarkan tegangan yang linier dengan pertambahan PWM. Dan alat ini berfokus kepada perebusan air untuk menghasilkan uap yang akan disalurkan ke steamer sehingga tidak dibahas tentang pengaruh pada jamur. 


\section{DAFTAR PUSTAKA}

Prananda, H. (2012). Prototype Sistem Pengendalian Dan Monitoring Suhu Dan Kelembaban Pada Media Tanam Jamur Tiram Berbasis Logika Fuzzy.

Putri, L. D. (2020). KAMPUNG JAMUR SEBAGAI BENTUK PEMBERDAYAAN MASYARAKAT DI CIKARAU KELURAHAN DADOK TUNGGUL HITAM KECAMATAN KOTO TANGAH KOTA PADANG. Comm-Edu (Community Education Journal), 3(2), 138-143.

Nurjanah, S. (2015). Pengaruh lama waktu inkubasi media terhadap produksi jamur tiram putih (pleurotus ostreatus) (Doctoral dissertation, IAIN Palangka Raya).

Witanto, B. (2013). PEMBUATAN SOSIS JAMUR TIRAM PUTIH (Pleurotus ostreatus Jacq.) DAN TEPUNG REBUNG DENGAN KOMBINASI TEPUNG TAPIOKA DAN KARAGINAN (Eucheuma cottonii Doty.) (Doctoral dissertation, UAJY).

Riwandi, R., Merakati, H., \& Hasanudin, H. (2014). Teknik Budidaya Jagung Dengan Sistem Organik Di Lahan Marjinal.

Ramdhani, A. H., \& Soelistyono, R. (2020). Pengaruh Lama Pengomposan pada Berbagai Suhu Sterilisasi Media Tanam terhadap Pertumbuhan dan Hasil Jamur Tiram Putih (Pleurotus ostreatus). Jurnal Produksi Tanaman, 8(3).

Purba, J. (2016). Perancangan Boiler Pipa Api untuk Perebusan Bubur Kedelai pada Industri Tahu Kapasitas Uap Jenuh $160 \mathrm{Kg} / \mathrm{Jam}$ (Doctoral dissertation, UNIVERSITAS PASIR PENGARAIAN KABUPATEN).

Rudiyanto, B., Susanto, A., \& Susmiati, Y. (2016). Aplikasi kontrol PI (proportional integral) pada katup ekspansi mesin pendingin. Rona Teknik Pertanian, 9(2), 89-105.

PUTRA, M. S. (2019). Pengaplikasian Sensor Warna pada Navigasi Line Tracking Robot Sampah berbasis Mikrokontroler (Doctoral dissertation, Politeknik Negeri Sriwijaya).

Naim, M. (2021). Buku Ajar Sistem Kontrol dan Kelistrikan Mesin. Penerbit NEM. 